\title{
Results of a 10 week community based strength and balance training programme to reduce fall risk factors: a randomised controlled trial in 65-75 year old women with osteoporosis
}

\author{
N D Carter, K M Khan, M A Petit, A Heinonen, C Waterman, M G Donaldson, \\ P A Janssen, A Mallinson, L Riddell, K Kruse, J C Prior, L Flicker, H A McKay
}

\begin{abstract}
Objective-To test the efficacy of a community based 10 week exercise intervention to reduce fall risk factors in women with osteoporosis.

Methods-Static balance was measured by computerised dynamic posturography (Equitest), dynamic balance by timed figure of eight run, and knee extension strength by dynamometry. Subjects were randomised to exercise intervention (twice weekly Osteofit classes for 10 weeks) or control groups.

Results-The outcome in 79 participants (39 exercise, 40 control) who were available for measurement 10 weeks after baseline measurement is reported. After confounding factors had been controlled for, the exercise group did not make significant gains compared with their control counterparts, although there were consistent trends toward greater improvement in all three primary outcome measures. Relative to the change in control subjects, the exercise group improved by $2.3 \%$ in static balance, $1.9 \%$ in dynamic balance, and $13.9 \%$ in knee extension strength.

Conclusions-A 10 week community based physical activity intervention did not significantly reduce fall risk factors in women with osteoporosis. However, trends toward improvement in key independent risk factors for falling suggest that a study with greater power may show that these variables can be improved to a level that reaches statistical significance. (Br F Sports Med 2001;35:348-351)
\end{abstract}

Keywords: osteoporosis; balance; strength; fall risk; exercise

Osteoporotic fracture is a major health care problem world wide, ${ }^{1}$ and falls are the major precipitant of hip ${ }^{23}$ and upper limb $b^{4}$ fractures. Certain fall risk factors such as impaired balance, abnormal gait patterns, ${ }^{56}$ and muscle weakness $^{7}$ respond favourably to physical activity. ${ }^{8-10}$

People with osteoporosis are often reluctant to join standard seniors exercise classes for fear of sustaining a low trauma fracture. Thus the Osteoporosis Program at BC Women's Hospital and Health Centre developed an exercise programme for people with osteoporosis. This programme began in 1997, and over 400 women have participated in it so far. To test its efficacy, we undertook a single blind, randomised controlled trial of a 10 week Osteofit exercise programme, in community dwelling women aged 65-75 years, who had osteoporosis confirmed by dual energy $x$ ray absorptiometry.

\section{Methods}

SUBJECTS

Subjects were community dwelling women who were aged 65-75 and had osteoporosis diagnosed by dual energy $x$ ray absorptiometry (Lunar Corp, Madison, Wisconsin, USA) at the total hip or lumbar spine or both - that is, bone mineral density $\mathrm{T}$ score at least 2.5 standard deviations below the young normal sex matched bone mineral density of the Lunar reference database. ${ }^{11}$ This group is described in more detail elsewhere (Carter N, et al. Quadriceps strength is a major determinant of static and dynamic balance as well as quality of life: a cross sectional study of 65-75 yr old community dwelling women with osteoporosis (submitted)).

After baseline measurements, 93 women were randomised to exercise intervention $(\mathrm{n}=$ $45)$ or control $(n=48)$ groups. Data reported are on the 79 women (39 control, 40 exercise) who were available for follow up 10 weeks after baseline measurement. The institutional review board approved the protocol, and all subjects gave written informed consent.

EXERCISE PROGRAMME: OSTEOFIT CLASSES

Osteofit is a community based exercise programme for people with osteoporosis; it aims to reduce the risk of falling and improve functional ability, and thereby enhance quality of life. The 
twice weekly exercise programme targets posture, balance, gait, coordination, and hip and trunk stabilisation. All instructors are registered by the $\mathrm{BC}$ recreation and parks association and certified by the BC Women's Hospital Osteoporosis programme. The classes for participants in this research study were typical of those in the Osteofit programme. The programme is outlined in more detail elsewhere (Carter et al. 'Osteofit' - a community-based strength and balance training program improves dynamic balance and knee extension strength: a randomized, single-blind controlled trial in 65-75 yr-old women with osteoporosis (submitted)) and at the website http://www.osteofit.org.

The main workout consisted of strengthening and stretching exercises to combat poor posture, as well as exercises to improve balance and coordination. Exercises to improve functional ability included chair squats and getting up and down off the floor. Exercise repetitions were kept between eight and 16, and the weights were relatively light so that the participants did not work to fatigue with each set. Each subject kept a journal in which they recorded their participation and any illness or injury. Subjects assigned to the control group were asked to continue their daily routine activities.

DESCRIPTIVE DATA

At baseline and 10 weeks, participants attended our hospital based laboratory to complete questionnaires and undertake physical testing.

QUESTIONNAIRES

We evaluated general health with a questionnaire, and current physical activity with the seven day physical activity recall questionnaire. ${ }^{12}$

BALANCE, STRENGTH, AND ANTHROPOMETRY

An experienced neuroscientist clinician (AM) performed all static balance measurements using the Equitest computerised posturography platform (Neurocom International, Clackamas, Oregon, USA) to determine response to sensory perturbations (Sensory Organisation Test). ${ }^{13}$ This instrument provides numerous measures of sway, and we used the composite balance score as an indicator of static balance. The test-retest reliability of composite score for computerised posturography is 0.98 (Pearson $r$ ).

Dynamic balance was tested by a timed figure of eight running test around two cones placed $10 \mathrm{~m}$ apart. ${ }^{14}{ }^{15}$ The best attempt of two trials was recorded. The result was converted into velocity $(\mathrm{m} / \mathrm{s})$ to simplify interpretation of

Table 1 Covariates for each dependent variable in analysis of covariance models for the 10 week randomised controlled Osteofit exercise intervention study

\begin{tabular}{ll}
\hline Dependent variable & Covariates \\
\hline $\begin{array}{l}\text { Dynamic balance change: change in } \\
\text { figure of } 8 \text { velocity }(\mathrm{m} / \mathrm{s})\end{array}$ & Age, physical activity (h/week), oestrogen use (years) \\
$\begin{array}{l}\text { Static posturography change: change in } \\
\text { Equitest composite score }\end{array}$ & $\begin{array}{l}\text { Rheumatoid arthritis (yes/no) and osteoarthritis } \\
\text { (yes/no) } \\
\text { Change in quadriceps strength }(\mathrm{kg} / \mathrm{cm})\end{array}$ \\
$\begin{array}{l}\text { Physical activity, mini-mental state score, lifetime } \\
\text { number of fractures }\end{array}$ \\
\hline
\end{tabular}

correlation and regression analysis. Positive correlation corresponds to improved dynamic balance.

The knee extension strength of the dominant leg was tested using Lord's strap assembly incorporating a strain gauge. ${ }^{16}$ Test-retest reliability in our laboratory for an age matched population $(\mathrm{n}=8)$ is 0.92 (Pearson $r$ ). For analysis, knee extension strength is expressed per unit of height to compensate for the length of the lever arm; all data reported here are thus corrected.

STATISTICAL ANALYSES

Data were analysed using SPSS (Windows version 8.0). Descriptive data are reported for variables of interest (mean, SD, and $95 \%$ confidence interval (CI)). Unpaired $t$ tests were used to compare baseline characteristics between groups and to assist in choosing covariates. Analysis of covariance was used to examine differences in percentage change between groups after controlling for confounding factors. Covariates were selected according to biological or statistical rationale. Multivariate analysis was used to search for confounding factors by adding independent variables to the model containing the "group" (exercise or control) variable and testing for a significant change in its coefficient (and therefore in the model adjusted $R^{2}$ ). For variables to be used in the final model, they had to produce a significant change in the group variable coefficient. Therefore covariates differed for each of the dependent variables (table 1).

We also constructed three stepwise regression models to determine the most robust predictors of change in (a) composite posturography score, $(b)$ figure of eight velocity $(\mathrm{m} / \mathrm{s})$, and $(c)$ knee extension strength. Independent variables of interest were: baseline value (for posturography, figure of eight, and knee extension strength respectively), age (years), number of current medications, oestrogen use (years), tobacco use (yes/no), height (cm), weight $(\mathrm{kg})$, current physical activity (hours), and Osteofit (yes/no). Variables were chosen on the basis of both theoretical and statistical (Pearson product-moment correlation) association with the outcome variables. Variables were entered into the model at $\mathrm{p}<0.10$.

\section{Results}

Exercise and control groups did not differ in baseline for age, height, and weight (table 2). The control group reported fewer years of oestrogen use, fewer medications, and higher activity levels at baseline. Although the differences were not significant, variables were considered as potential covariates in the analyses.

Absolute (table 3) and percentage (fig 1) change for knee extension strength and static and dynamic balance for each group after controlling for confounding factors are summarised. Adjusted for covariates the exercise group improved in static balance by a mean (SE) $3.6(1.7) \%$ whereas the control group improved $1.3(1.7) \%$. Similar non-significant trends were seen in dynamic balance (exercise group improved 6.9 (1.7)\% and control 5.0 
Table 3 Absolute change in strength and dynamic and static balance over 10 weeks for exercise and control groups in the randomised controlled Osteofit study

\begin{tabular}{lcll}
\hline & Control $(n=39)$ & Exercise $(n=40)$ & $\begin{array}{l}p \text { Value for } \\
\text { group } \\
\text { differences }\end{array}$ \\
\hline Figure of eight $(\mathrm{m} / \mathrm{s})$ & $0.09(0.1$ to 0.17$)$ & $0.14(0.07$ to 0.21$)$ & 0.310 \\
Quad $/ \mathrm{Ht}(\mathrm{kg} / \mathrm{cm})$ & $-0.48(-1.47$ to 0.51$)$ & $0.44(-0.55$ to 1.42$)$ & 0.203 \\
Equitest composite & $0.60(-1.33$ to 2.52$)$ & $1.79(-0.11$ to 3.70$)$ & 0.387
\end{tabular}

Values are mean (95\% confidence intervals) adjusted for covariates. Covariates are for: (1) quadriceps strength: activity, mini-mental state score, and lifetime number of fractures; (2) figure of eight: age, physical activity level, and years of oestrogen use; (3) Equitest: rheumatoid arthritis and osteoarthritis.

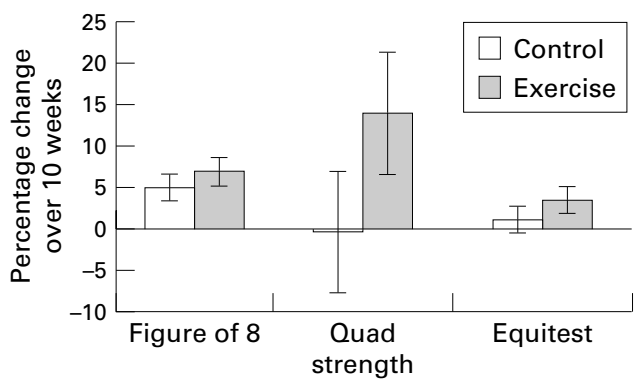

Figure 1 Percentage change over 10 weeks for exercise and control groups for figure of eight velocity, knee extension strength, and Equitest. Means are adjusted for covariates (see table 1). Bars are adjusted means and SE.

$(1.7) \%)$ and in knee extension strength (exercise group improved $13.9(7.3) \%$ and control decreased by $0.2(7.3) \%$ ) (fig 1$)$.

Participants reported no injuries from either measurement or the exercise intervention. Mean compliance with the exercise intervention as measured by instructor log was $78 \%$, and the range was $44-100 \%$ of possible sessions attended.

\section{STEPWISE REGRESSION}

Table 4 shows models predicting change in static and dynamic balance and quadriceps

Table 2 Baseline characteristics in those completing the 10 week trial between exercise and control groups in the Osteofit randomised controlled trial

\begin{tabular}{lrrrl}
\hline & Control $(n=39)$ & Exercise $(n=40)$ & p Value \\
\hline Age (years) & $70.8(4.0)$ & $71.6(3.9)$ & 0.353 \\
Height (cm) & $157.0(5.1)$ & $156.8(7.5)$ & 0.892 \\
Weight (kg) & $59.0(11.3)$ & $63.6(12.4)$ & 0.089 \\
Oestrogen use (years) & $2.5(5.3)$ & $3.6(5.5)$ & 0.386 \\
Medications (No) & $2.0(1.5)$ & $2.6(1.6)$ & 0.127 \\
Activity & $15.0(18.4)$ & $9.2(9.1)$ & 0.079 \\
Quality of life (total) & $27.1(13.8)$ & $28.3(13.7)$ & 0.680 \\
Quad/Ht (kg/cm) & $15.7(4.4)$ & $15.4(5.9)$ & 0.783 \\
Figure of eight (m/s) & $1.64(0.34)$ & $1.51(0.71)$ & 0.289 \\
Equitest composite score & $72.8(8.5)$ & $72.5(10.4)$ & 0.881
\end{tabular}

Values are mean (SD).

Table 4 Stepwise regression models for change in quadriceps strength $(\mathrm{kg} / \mathrm{cm})$, static posturography (Equitest), and dynamic balance (using the figure of eight test in $\mathrm{m} / \mathrm{s}$ ) including standardised $\beta$ coefficients and adjusted $R^{2}$

\begin{tabular}{llll}
\hline 10 week change in the variable & Predictor & Standardised $\beta$ & Adjusted $R^{2}$ \\
\hline Static balance (Equitest) & Baseline (Equitest) & $-0.52^{\star}$ & 0.26 \\
(composite score) & Baseline (seconds) & $-0.86^{\star}$ & 0.42 \\
Dynamic balance & Medications (number) & $0.26^{\star}$ & 0.47 \\
(figure of eight velocity) & Age (years) & $0.21^{\star \star}$ & 0.50 \\
& Height (cm) & $-0.15^{\star \star \star}$ & 0.51 \\
Knee extension strength & Baseline (g/cm) & $-0.46^{\star}$ & 0.23 \\
(g/cm corrected for height) & Physical activity (h/week) & $0.27^{\star}$ & 0.33 \\
& Oestrogen (years) & $0.22^{\star \star}$ & 0.37 \\
& Age (years) & $0.22^{\star \star}$ & 0.41
\end{tabular}

Variables entered: baseline value (Equitest, figure of eight, or quad strength respectively), age (years), medications (number of current), tobacco $(1=$ yes, $0=$ no), height $(\mathrm{cm})$, weight $(\mathrm{kg})$, oestrogen use (years), current physical activity (h/week), and Osteofit $(1=$ yes, $0=$ no). ${ }^{\star} \mathrm{p}<0.01,{ }^{\star \star} \mathrm{p}<0.05,{ }^{\star \star \star} \mathrm{p}<0.10$ (in final model). strength. Baseline values explained a significant amount of the variance in each of the three regression models. Physical activity explained $10 \%$ of the variance in knee extension strength.

\section{Discussion}

This randomised controlled trial in 79 women with proven osteoporosis showed that a 10 week community based exercise intervention was safe in such women but that it did not promote statistically significant improvement in static balance, dynamic balance, or knee extension strength. Each of these three outcome variables is an independent risk factor for osteoporotic fracture. ${ }^{7}$ However, it is important to note that certain participants made substantial gains, and the mean increase in strength of almost $14 \%$ in knee extension strength is likely to be of biological significance, if not statistical significance, in this relatively small study. Furthermore, negative studies need to be reported to avoid publication bias and to help to define the dimensions of exercise that cause significant improvements in fall risk factors.

There is increasing demand for exercise studies to define clearly the dimensions of exercise needed to ameliorate health. This 10 week analysis indicates that such a short intervention may be of insufficient duration to substantially alter the fall risk profile in women with osteoporosis. This does not exclude the possibility that a longer intervention may achieve such a result.

We note several study limitations. Exercise intervention studies appeal to those who are healthy and motivated, ${ }^{17}$ and women who volunteered for this study were particularly fit for their age. This limits the population to which results can be generalised. Particularly frail women (in addition to having osteoporosis) may not be able to attend community based intervention.

We acknowledge that improving a fall risk factor profile does not guarantee fall reduction. There is a need for a larger study to evaluate the effect of this type of intervention in a high risk group that is powered to detect a treatment effect on falls, and ideally, injurious falls and fractures. ${ }^{18}$

The clinical implication of this study is that appropriately supervised community based exercise classes can be safe for patients with osteoporosis. However, 10 weeks appears to be too short to achieve statistically significant change in some important outcomes. Nevertheless, the trends we observed suggest that analysis of a longer intervention is warranted.

1 Kanis JA, Melton III L, Christiansen C, et al. The diagnosis of osteoporosis. $\mathcal{F}$ Bone Miner Res 1994;9:1137-41.

2 Parkkari J, Kannus P, Palvanen M, et al. Majority of hip fractures occur as a result of a fall and impact on the greater trochanter of the femur: a prospective controlled hip fracture study with 206 consecutive patients. Calcif Tissue Int 1999;65:183-7.

3 Grisso JA, Kelsey JL, Strom BL, et al. Risk factors for falls as a cause of hip fractures in women. Lancet 1991;324:132631.

4 Haboubi NY, Hudson PR. Factors associated with Colles' fracture in the elderly. Gerontology 1991;37:335-8.

5 Lord SR, Sherrington C, Menz HB. Falls in older people: risk factors and strategies for prevention. Cambridge: Cambridge University Press, 2001. 
6 Dargent-Molina P, Favier F, Grandjean H, et al. Fall-related factors and risk of hip fracture: the EPIDOS prospective study.

7 Nguyen TV, Sambrook PN, Kelly PJ, et al. Prediction of osteoporotic fractures by postural instability and bone density. BMF 1993;307:1111-15.

8 Carter N, Kannus P, Khan KM. Exercise and the prevention of falls in older people: a systematic literature review of the rationale and the evidence. Sports Med 2001;31:427-38.

9 Gardner MM, Robertson MC, Campbell AJ. Exercise in preventing falls and fall related injuries in older people: a review of randomised controlled trials. $\mathrm{Br} \mathcal{F}$ Sports Med 2000;34:7-17.

10 Khan K, McKay H, Kannus P, et al. Physical activity and bone health. Champaign, IL: Human Kinetics, 2001.

11 WHO Study Group. Assessment of fracture risk and its application to screening for postmenopausal osteoporosis. application to screening for postmenopaus

12 Blair S, Haskell W, Ho P, et al. Assessment of habitual physical activity by a seven day recall in a community survey and $\mathrm{cal}$ activity by a seven day recall in a community survey and
controlled experiments. Am $\mathcal{F}$ Epidemiol 1985;122:794-804.
13 Whipple R, Wolfson L, Derby C, et al. Altered sensory function and balance in older persons. F Gerontol 1993; 48(special No):71-6.

14 Tegner Y, Lysholm J, Gillquist J. A performance test to monitor rehabilitation and evaluate anterior cruciate ligament injuries. Am f Sports Med 1986;14:156-9.

15 Heinonen A, Kannus P, Sievänen H, et al. Randomised control trial of effect of high-impact exercise on selected risk factors of osteoporotic fractures. Lancet 1996:348:1343-7.

16 Lord SR, Ward JA, Williams P, et al. The effect of a 12 -month exercise trial on balance, strength, and falls in older women: a randomized controlled study. 7 Am Geriatr Soc 1995;43:1198-206.

17 Pacala JT, Judge JO, Boult C. Factors affecting sample selection in a randomized trial of balance enhancement: the FICSIT Study. $f$ Am Geriatr Soc 1996;44:377-82.

18 Khan K, T Liu-Ambrose, Donaldson M, et al. Physical activity to prevent falls in older people: time to intervene in high-risk groups using falls as an outcome. Br 7 Sports Med 2001;35:144-5.

\section{Take home message}

Community based exercise classes can be safe for patients with osteoporosis, and such a programme produced trends toward increased knee extension strength, static balance, and dynamic balance in 65-75 year old women. However, the 10 week intervention did not achieve statistically significant changes in the fall risk profiles of the participants.

\section{BASEM Merchandise 2001}

Ties

Multi motif

$£ 6+£ 1.50 \mathrm{p} \& \mathrm{p}$

New stock to order

Sweaters

Lambswool fine knit, V-neck or round

$£ 32+£ 3 \mathrm{p} \& \mathrm{p}$

neck with small motif. Machine washable.

State colour and chest size required.

Sweatshirts

With small motif.

State colour and chest size required.

Polo shirts

With small motif.

State colour and chest size required.

$£ 25+£ 3 \mathrm{p} \& \mathrm{p}$

$£ 23+£ 3 \mathrm{p} \& \mathrm{p}$

Send orders to John H Clegg JP BSc (Hons) DipEcon (Open) LDS RCS Eng, Hon Secretary, Birch Lea, 67 Springfield Lane, Eccleston, St Helens, Merseyside WA10 5HB, UK. (Tel and Fax: 01744 28198) 